\author{
M. Büchert • M. W. Greenlee • Roland M. Rutschmann • \\ F. M. Kraemer $\cdot$ Feng Luo $\cdot$ J. Hennig
}

\title{
Functional magnetic resonance imaging evidence for binocular interactions in human visual cortex
}

Received: 13 September 2000 / Accepted: 26 March 2002 / Published online: 22 June 2002

(C) Springer-Verlag 2002

\begin{abstract}
Using functional magnetic resonance imaging (fMRI), we explored the binocular interactions occurring when subjects viewed dichoptically presented checkerboard stimuli. A flickering radial checkerboard was presented to each eye of the subject, while $\mathrm{T} 2 *$-weighted images were acquired over the visual cortex with gradient-echo, echoplanar sequences. We compared responses in striate and extrastriate visual cortex under four conditions: both eyes were stimulated at the same time (binocular condition), each eye was stimulated in alternation (monocular condition) or first the one eye then the other eye was stimulated (left eye first - right eye trailing, or vice versa). The results indicate that only the striate area, in and near the calcarine fissure, shows significant differences for these stimulation conditions. These differences are not evident in more remote extrastriate or associational visual areas, although the BOLD response in the stimulation-rest comparison was robust. These results suggest that the effect could be related to inhibitory interactions across ocular dominance columns in striate visual cortex.
\end{abstract}

Keywords Visual cortex - Ocular dominance columns . Binocular interactions - fMRI - BOLD effect - Dichoptic stimulation

\section{Introduction}

We view the world with two eyes. Although we cannot consciously discriminate between input from the left or

\author{
M. Büchert ( $)$ - F.M. Kraemer · F. Luo · J. Hennig \\ Department of Radiology/Section of MR Physics, \\ University Hospital Freiburg, Hugstetterstr. 55, 79106 Freiburg, \\ Germany \\ e-mail: buechert@uni-freiburg.de \\ Tel.: +49-761-2707395 \\ Fax: +49-761-2703831
}

M.W. Greenlee · R.M. Rutschmann Institute for Cognitive Science, University of Oldenburg, 26111 Oldenburg, Germany right eye when both eyes are open, the signals from each eye are carefully separated up to and including the initial terminals in layer 4 of primary visual cortex (Hubel and Wiesel 1968). In most cells in other layers of striate cortex and those in extrastriate cortex, the signals from each eye are combined, such that the neurons can be activated by stimuli presented to either eye. Independent stimulation of the left and right eyes has been used in the past to explore the responses of neurons having receptive fields that can be exclusively driven by the one or the other eye (monocular receptive fields) or by both eyes (binocular receptive fields). In primary visual cortex, neurons receiving input from the one or the other eye are systematically organized into ocular dominance columns. Tangential penetrations with a recording microelectrode through primary visual cortex in macaques reveal that these ocular dominance columns are spaced approximately $0.5 \mathrm{~mm}$ apart (Hubel and Wiesel 1977). Anatomical studies using reduced silver staining techniques have supported these findings (LeVay et al. 1975), as have optical recording techniques (Grinvald et al. 1986; Malonek et al. 1997).

Functional magnetic resonance imaging (fMRI) techniques have developed rapidly over the last 10 years. The use of the paramagnetic deoxygenated hemoglobin as an endogenous contrast substance has allowed the noninvasive imaging of blood flow and blood oxygenation changes in rat (Ogawa et al. 1990, 1993), cat (Kim et al. 2000), monkey (Logothetis et al. 1999, 2001) and human cortex (Kwong et al. 1992; Turner et al. 1993). Few studies have attempted to map the ocular dominance columns, since the current resolution of fMRI is considerably less than that required to resolve the underlying neural substrate. Menon et al. (1997; Menon and Goodyear 1999) reported evidence for the ocular dominance columns in human subjects with high-field (4 T) MRI. These authors found alternating strips containing voxels, the intensity of which was greater for left or right eye stimulation, respectively. Independent confirmation of this pattern of BOLD responses to left and right eye 
stimulation has been recently reported (Cheng et al. 2001).

We provide indirect evidence for binocular interactions in striate and extrastriate cortex using an echoplanar imaging (EPI) sequence at $1.5 \mathrm{~T}$ and an in-plane voxel resolution of $2 \times 2 \mathrm{~mm}$. By sequentially stimulating either the left or the right eye in an alternating fashion, we found differences between striate and extrastriate cortex, which are indicative of binocular interactions. These interactions are not present in areas beyond V1, where the afferent signals from the two eyes are combined.

\section{Materials and methods}

Magnetic resonance imaging

Magnetic resonance imaging was performed with a 1.5-T Siemens Magnetom Vision clinical whole body scanner. The scanner was equipped with an EPI booster with a gradient system having $25 \mathrm{mT} /$ $\mathrm{m}$ amplitude and $0.3 \mathrm{~ms}$ rise time and a full-head radiofrequency (RF) receive-transmit headcoil. High-resolution, sagittal T1weighted images were acquired with the MP-RAGE (magnetization prepared, rapid acquisition gradient echo) sequence to obtain a 3D anatomical model of the head and brain. The anatomical data set consisted of $256 \times 256 \times 160$ voxels with a voxel size of $1 \mathrm{~mm}^{3}$. We defined the anterior-posterior commissural (AC-PC) plane (Talairach and Tournoux 1988) and report all findings in this coordinate system. Shimming was performed for the entire brain using an auto-shim routine, which yielded satisfactory magnetic field homogeneity.

Functional imaging was performed with $\mathrm{T} 2 *$-weighted gradient recalled EPI. The technical data for the functional measurements were as follows: TE $66 \mathrm{~ms}$, TR $3 \mathrm{~s}$, flip angle $90 \mathrm{deg}$, field of view $256 \mathrm{~mm}$, matrix $128 \times 128$ (voxel size $=2 \times 2 \times 4 \mathrm{~mm}^{3}$ ). Ten or twelve 4-mm planes, positioned oblique to the axial plane, were imaged every $3 \mathrm{~s}$. The position of the acquired volume for the fMRI measurements is illustrated for one subject in Fig. 1.

To minimize head motion, the subject's head was fixed with a vacuum cap, which was secured by temple rests within the headcoil. Despite these precautions, residual head motion was still evident in some of the image data. Head motion could be corrected by applying an image alignment algorithm (SPM99). Excessive head motion was evident in three subjects and their data were removed from further analysis. Subjects wore either ear plugs or sound-dampening headphones to reduce the effects of the gradient noises.

\section{Visual stimulation}

The stimuli were created on a Visual Stimulus Generator graphics card (Cambridge Research Ltd.) and projected with an LCD projector (Panasonic) onto a back-projection screen, which was mounted at the back of the gantry. The image subtended $30 \times 30 \mathrm{deg}$ of visual angle $(800 \times 600$ pixels) at a viewing distance of $1.3 \mathrm{~m}$. The mean luminance of the display was constant throughout at $100 \mathrm{~cd} / \mathrm{m}^{2}$

The stimuli were presented dichoptically using polar filters and adjustable right-angle prisms for optical superimposition of the right and left image as shown in Fig. 1.

The stimuli were radial checkerboards, in which the highluminance contrast $(0.9)$ checks exchanged position $(8 \mathrm{~Hz}$, phasereversing) as a sinusoidal function of time. During rest (baseline) periods, subjects viewed a small black fixation mark superimposed onto a homogeneous field (mean luminance $=100 \mathrm{~cd} / \mathrm{m}^{2}$ ). They were requested to maintain binocular fusion of the small fixation mark, which was located in the center of each ocular image. No horizontal disparity was introduced, so the images appeared in a single plane.

The experimental paradigm contained five different epochs:

- Alternating monocular stimulation [A]

- Simultaneous binocular stimulation [B]

- Left eye leading - right eye trailing [LR]

- Right eye leading - left eye trailing [RL]

- Baseline (compare Fig. 2)

Each rest epoch (30 s) was followed by one of the described epochs of checkerboard stimulation. The complete sequence of one repetition is shown in Fig. 2. Three to four repetitions of the experiment were performed for each subject.

Data processing and visualization

For all subjects the functional data were realigned, coregistered to the anatomical data, normalized to the standard Montreal Neurological Institute (MNI) T1-weighted template and smoothed with a gaussian (FWHM=6 mm) using SPM99 (Friston et al. 1995a). We also used SPM99 to create time profiles (box car convoluted with the expected hemodynamic response profile) for each of the four

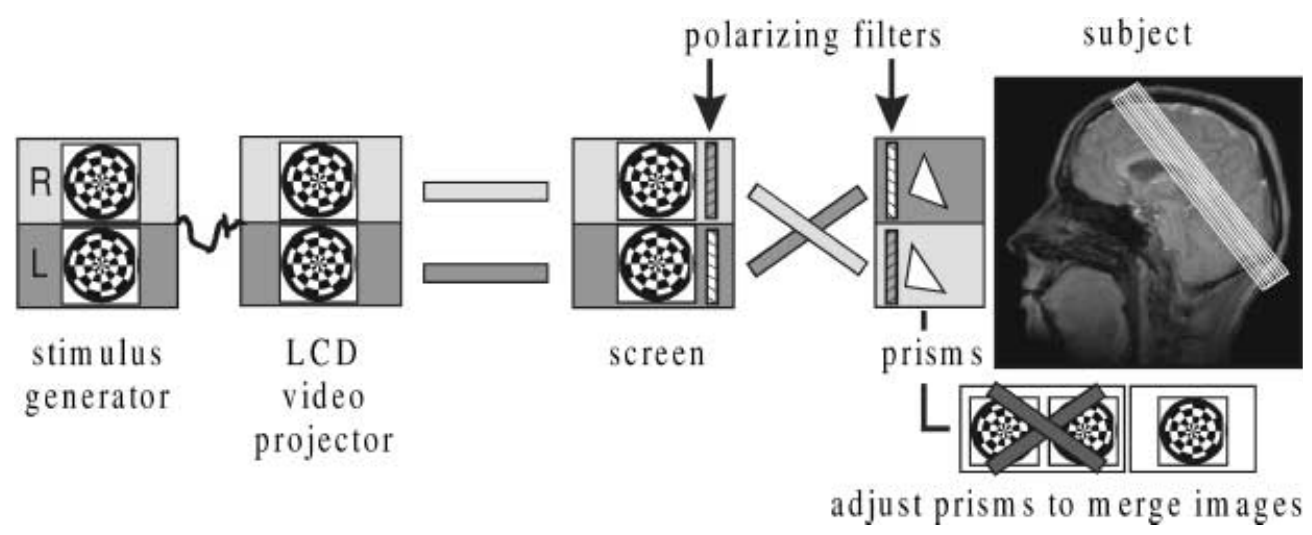

Fig. 1 Schematic illustration of the experimental setup designed to investigate binocular interactions. The left half shows the radial checkerboard patterns presented on the left and right sides of the back-projection screen. The subject viewed the screen through adjustable prisms equipped with polarizing filters. Matched polar- izing filters were positioned in front of the screen so that each eye obtained an image from the respective side. By manually adjusting the prisms the subject could optically superimpose the two images to create a single dichoptic image. In the right half of the figure the position of the EPI volume in one subject is shown 
stimulus conditions (A, B, RL, and LR) and calculated the amount of $\mathrm{T} 2 *$ signal variance that could be explained by each of the given profiles (Friston et al. 1995b; Friston 1996). Subsequently we will concentrate only on areas which show differences in activation during conditions A and B (i.e., areas in which BOLD contrast was higher during stimulus $\mathrm{A}$ than during stimulus $\mathrm{B}$ and vice versa). For identification of anatomical sites, MNI coordinates were converted to Talairach coordinates (using the script mni2tal, http:// www.mrc-cbu.cam.ac.uk/Imaging/mnispace.html). Then anatomical identification was done using the Talairach atlas (Talairach and Tournoux 1988), the Talairach Demon (Lancaster et al. 2000) and the anatomical overlays of the normalized subjects' anatomical scans. We overlaid the functional regions of interest (ROIs) onto the averaged normalized brain of all 14 subjects for visualization using Krish Singh's mri3dX (http://www-users.aston.ac.uk/ $\sim$ singhkd/mri3dX/; see also Smith et al. 1998). Time course plots were done by defining ROIs of six highly activated voxels averaging the plots over the same conditions using an SMP tool by Kalina Christoff (http://www.psych.stanford.edu/ kalina/ SPM99/Tools/roi.html), which we adapted for our needs.

Subjects

After giving their informed consent, 17 (12 male, 5 female) volunteers participated in the study. The subjects were naive with respect to the experimental hypotheses under investigation. They were instructed to maintain binocular fusion and to attend to the stimuli. They were instructed to press a button if they were unable to maintain binocular fixation or experienced difficulties in restricting their attention to the stimuli. The subject's age ranged from 19 to 50 years, mean age 29.3 years. One volunteer was left handed, while all other subjects were right handed. The data of three subjects could not be evaluated due to pronounced motion artifacts even after motion correction. These data were subsequently removed from the study.

\section{Results}

Figure 2 (lower panel) shows, for one subject, the time course of individual ROIs within the primary visual cortex and compares this to the time course of a voxel cluster in a more remote extrastriate area. The voxel cluster within the primary visual cortex (V1) responds best when each eye is stimulated in alternating sequence (i.e., during condition A). Overall we found highly significant (corrected $P<0.001$ ) activation compared to rest, which is spread bilaterally over the entire occipital cortex, with a total of more than 3,500 activated voxels. The amplitude of the response is less when both eyes are stimulated at the same time (binocular condition B), though the spatial extent of activation is comparable. An intermediate level of activation is evident during the LR and RL conditions, respectively. Since the overall stimulation period remains the same for both conditions, these differences must be related to binocular interactions. As the subject is unaware of which eye is being stimulated at a given phase of the experiment, we can rule out that these differences could be related to the subject attending more in one stimulation condition than the others.

In the stimulation-rest comparisons, significant voxel clusters were found in Brodmann's areas (BA) 17 and 18 (corresponding approximately to V1 and V2), BA 19 (V3, dorsal cuneus), the ventroposterior area (VP) and the occipitotemporal junction region in BA37 (V5) bilaterally. Table 1 presents the Talairach coordinates (Talairach and Tournoux 1988, reported in millimeters deviation from the anterior commissure) for voxel clusters with significant activation. Contrary to the overall activation in visual cortex, only area V1 showed a cluster that was significantly more activated by the alternating monocular condition. The time course of this activation for the four stimulation conditions is displayed in Fig. 3. As expected the two intermediate conditions (LR and RL) evoke a level of activation that lies between the alternating and binocular conditions.
Fig. 2 Upper panel: Time course of activation for the four stimulus epochs ( $B$ binocular, $M$ monocular, $R L$ right eye stimulated first, followed by left eye stimulation, $L R$ left eye stimulated first, followed by right eye stimulation). During the stimulation period, the subjects perceived a single flickering radial checkerboard, whereas during the rest period they viewed a single black fixation mark. The mean luminance in all conditions was constant. Lower panel: Typical time courses from regions of interest (ROIs) centered in one hemisphere in the primary visual cortex $(V I)$ or in an extrastriate region. Results are from one subject
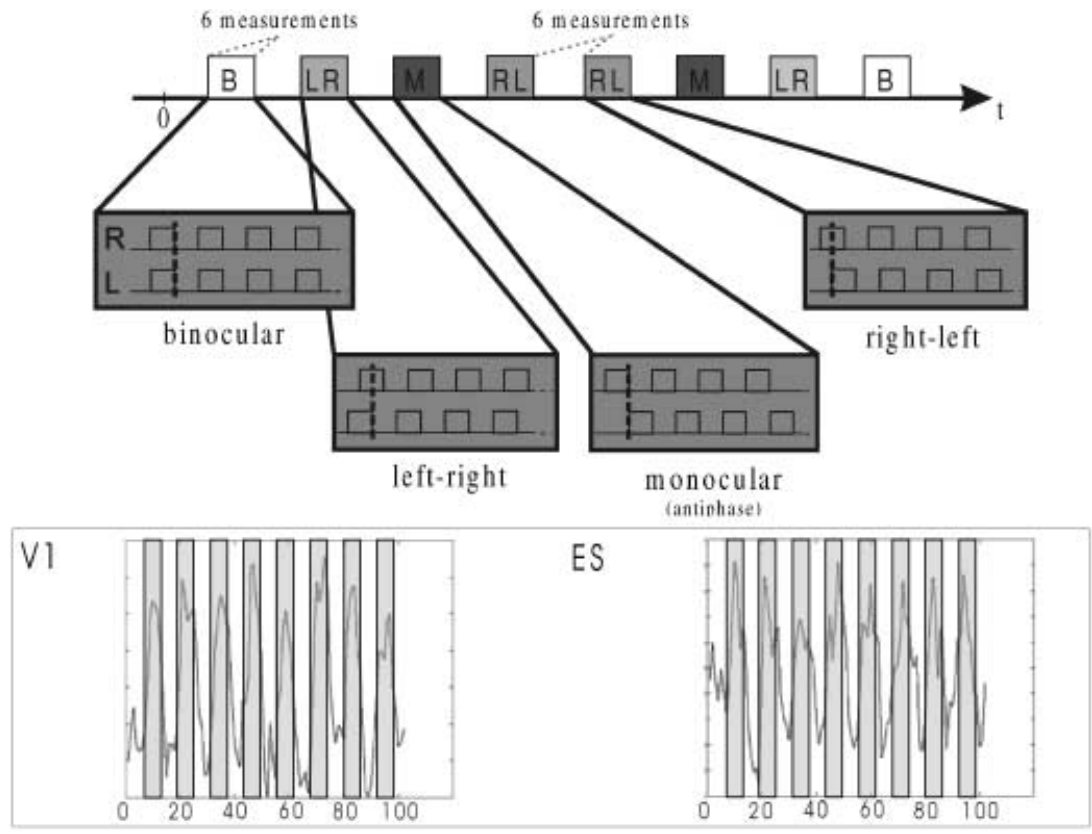
Table 1 Talairach coordinates (Talairach and Tournoux 1988) (in millimeters deviation from the anterior commissure) for voxel clusters with significant activation

Fig. 3 Time course of the mean BOLD response (shown as normalized activation in percent signal change) for 14 subjects. The different curves present the results from the four stimulus conditions

\begin{tabular}{|c|c|c|c|c|c|c|c|c|c|}
\hline & \multicolumn{3}{|c|}{ Talairach } & \multicolumn{3}{|l|}{ Cluster } & \multicolumn{3}{|l|}{ Voxel } \\
\hline & $x$ & $\mathrm{y}$ & $z$ & $P($ corr $)$ & $k$ & $P$ (uncorr) & $P($ corr $)$ & $T$ & $Z$ \\
\hline \multicolumn{10}{|l|}{ Alternating $>$ binocular } \\
\hline Lingual-gyrus & 16 & -91 & -4 & 0 & 149 & 0 & $\begin{array}{l}0 \\
0.001\end{array}$ & $\begin{array}{l}5.47 \\
5.13\end{array}$ & $\begin{array}{l}5.46 \\
5.12\end{array}$ \\
\hline Middle occipital gyrus & -34 & -91 & 10 & 0.038 & 11 & 0.055 & 0.005 & 4.83 & 4.82 \\
\hline Inferior occipital gyrus & -26 & -92 & -7 & 0.017 & 16 & 0.024 & 0.013 & 4.61 & 4.6 \\
\hline Lingual gyrus & $\begin{array}{r}-12 \\
38\end{array}$ & $\begin{array}{r}-94 \\
84\end{array}$ & $\begin{array}{l}-5 \\
-4\end{array}$ & $\begin{array}{l}0.004 \\
0.045\end{array}$ & $\begin{array}{l}26 \\
10\end{array}$ & $\begin{array}{l}0.006 \\
0.066\end{array}$ & $\begin{array}{l}0.048 \\
0.118 \\
0.19\end{array}$ & $\begin{array}{l}4.27 \\
4.02 \\
3.87\end{array}$ & $\begin{array}{l}4.27 \\
4.02 \\
3.87\end{array}$ \\
\hline \multicolumn{10}{|l|}{ Binocular $>$ alternating } \\
\hline Lingual gyrus & -12 & -79 & 6 & 0 & 136 & 0 & $\begin{array}{l}0.001 \\
0.001 \\
0.003\end{array}$ & $\begin{array}{l}5.31 \\
5.2 \\
4.91\end{array}$ & $\begin{array}{l}5.3 \\
5.19 \\
4.9\end{array}$ \\
\hline Cuneus & 0 & -75 & 18 & 0 & 64 & 0 & 0.001 & 5.14 & 5.13 \\
\hline Posterior cingulate & 31 & -73 & 13 & 0.017 & 16 & 0.024 & 0.01 & 4.68 & 4.67 \\
\hline Middle occipital gyrus & 51 & -72 & 7 & 0.045 & 10 & 0.066 & 0.025 & 4.44 & 4.43 \\
\hline
\end{tabular}
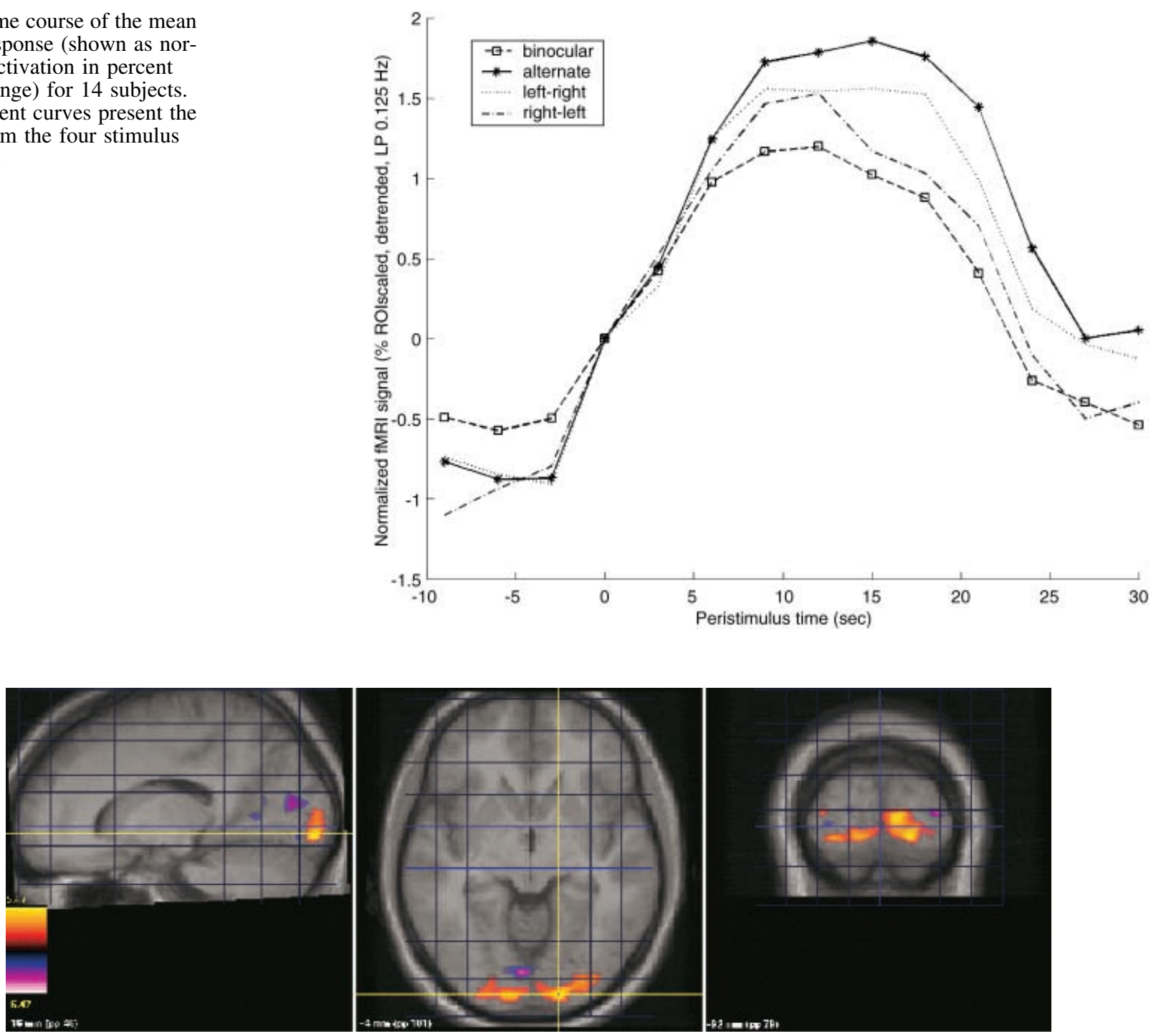

Fig. 4 Statistical parametric maps of the significant BOLD responses to alternating monocular stimulation compared to the binocular condition. Voxels in orange red indicate regions that responded more strongly to the alternating monocular stimulus, whereas those shown in blue depict regions more responsive to the binocular condition. The cross hairs represent the most active voxel within the cluster. The color key presents the $Z$-scores 
Figure 4 presents the results of the SPM analysis as activation maps overlaid onto the average anatomical images. A large voxel cluster located in and near the calcarine fissure indicates a significant enhancement of BOLD response in favor of the alternating monocular stimulation. The location of the voxel cluster corresponding to higher activation during binocular stimulation is in extrastriate cortex.

\section{Discussion}

Our results suggest that binocular interactions can be revealed by fMRI and that these effects are most pronounced in primary visual cortex. Compared to alternating monocular stimulation, simultaneous binocular stimulation led to lower BOLD responses. Our findings indicate that standard field $(1.5 \mathrm{~T})$ strength is sufficient to isolate BOLD contrast in visual cortex related to monocular and binocular stimulation. These results are consistent with those gained with high-field (4T) imaging (Menon et al. 1997; Menon and Goodyear 1999; Cheng et al. 2001). The size of the BOLD effect on binocular and alternating monocular stimulation (i.e., $1.2 \%$ and $1.8 \%$ respectively; cf. Fig. 3 ) is remarkably similar to the effect sizes reported by Menon and Goodyear (1999).

Our use of a high-contrast radial checkerboard pattern was designed to stimulate neurons tuned to both high and low spatial frequencies. Although the stimuli we used clearly evoked activation in extrastriate areas (see Table 1), motion stimuli would most likely lead to a stronger response in these lateralized areas (Tootell et al. 1995, 1997; Smith et al. 1998).

The differences presented in Fig. 3 are consistent with the idea that striate cells in ocular dominance columns interact when they are simultaneously activated. This binocular interaction is reduced by stimulation of each eye in alternation and, as a consequence, the BOLD response becomes larger. Such binocular interactions could be related to the mechanism of binocular rivalry, which is evoked when the two eyes are presented with different images (Blake and Logothetis 2002). Further investigation is required that uses images of different size or orientation to induce rivalry (Lumer et al. 1998). A recent model suggests that the timing of action potentials from neurons responding to stimuli in the one or other eye might be an important cue in binocular rivalry (Lumer 1999).

The effects of binocular disparity on the responses of cells in cat (Ohzawa et al. 1997) and monkey (Poggio and Fischer 1977) have been described. Although we did not introduce disparity into the stimuli, slight misalignment of the two eyes could have led to false correspondence between points in the retinal images. We trained subjects to maintain fixation throughout the scan period, but did not monitor the binocular eye movements. Recent work in our laboratory (Rutschmann and Greenlee, submitted for publication) and elsewhere (Backus et al. 2001), which employs random-dot stereograms, suggests that area V3 is an important site for the processing of disparity.

\section{Conclusion}

The present results provide evidence for binocular interactions in human visual cortex. They suggest that fMRI can reveal neural interactions that occur at the cellular level. This approach might find interesting applications in the study of developmental disorders of binocular vision.

Acknowledgements This work was funded by the Deutsche Forschungsgemeinschaft (DFG, Gr 988/15 and SFB 517, C9). M.W. Greenlee was supported by the Hermann and Lilly Schilling Foundation, Germany. The authors would like to thank the volunteers for their participation.

\section{References}

Backus BT, Fleet DJ, Parker AJ, Heeger DJ (2001) Human cortical activity correlates with stereoscopic depth perception. J Neurophysiol 86:2054-2068

Bandettini PA, Wong EC, Hinks RS, Tikofsky RS, Hyde JS (1992) Time course EPI of human brain function during task activation. Magn Reson Med 25:390-397

Blake R, Logothetis NK (2002) Visual competition. Nat Rev Neurosci 3:13-21

Cheng K, Waggoner RA, Tanaka K (2001) Human ocular dominance columns as revealed by high-field functional magnetic resonance imaging. Neuron 32:359-374

Cox R (1996) AFNI: software for analysis and visualization of functional magnetic neuroimages. Comput Biomed Res 29:162-173

Friston KJ (1996) Statistical parametric mapping and other analysis of functional imaging data. In: Toga AW, Mazziotta JC (eds) Brain mapping. The methods. Academic Press, San Diego, pp 363-388

Friston KJ, Ashburner J, Poline JB, Frith CD, Heather JD, Frackowiak RSJ (1995a) Spatial registration and normalization of images. Hum Brain Mapp 2:165-189

Friston KJ, Holmes AP, Worsley KJ, Poline JP, Frith CD, Frackowiak RSJ (1995b) Statistical parametric maps in functional imaging: a general linear approach. Hum Brain Mapp $2: 189-210$

Friston KJ, Holmes AP, Poline JB, Grasby PJ, Williams SC, Frackowiak RS, Turner R (1995c) Analysis of fMRI time-series revisited. Neuroimage 2:45-53

Grinvald A, Lieke E, Frostig RD, Gilbert CD, Wiesel TN (1986) Functional architecture of cortex revealed by optical imaging of intrinsic signals. Nature 324:361-364

Hubel DH, Wiesel TN (1968) Receptive fields and functional architecture of monkey striate cortex. J Physiol 195:215-243

Hubel DH, Wiesel TN (1977) Functional architecture of macaque monkey visual cortex. Proc R Soc Lond 198:1-59

Kim DS, Duong TQ, Kim SG (2000) High-resolution mapping of iso-orientation columns by fMRI. Nature Neurosci 3:164-169

Kwong KK, Belliveau JW, Chesler DA, Goldberg IE, Weiskoff RM, Poncelet BP, Kennedy DN, Hoppel BE et al. (1992) Dynamic magnetic resonance imaging of human brain activity during primary sensory stimulation. Proc Natl Acad Sci U S A 89:5675-5679

Lancaster JL, Woldorff MG, Parsons LM, Liotti M, Freitas CS, Rainey L, Kochunov PV, Nickerson D, Mikiten SA, Fox PT (2000) Automated talairach atlas labels for functional brain mapping. Hum Brain Mapp 10:120-131 
LeVay S, Hubel DH, Wiesel TN (1975) The pattern of ocular dominance columns in macaque visual cortex revealed by reduced silver stain. J Comp Neurol 159:559-576

Logothetis NK, Guggenberger H, Peled S, Pauls J (1999) Functional imaging of the monkey brain. Nat Neurosci 2:555-562

Logothetis NK, Pauls J, Augath M, Trinath T, Oeltermann A (2001) Neurophysiological investigation of the basis of the fMRI signal. Nature 412:128-130

Lumer ED (1999) A neural model of binocular integration and rivalry based on the coordination of action potential timing in primary visual cortex. Cereb Cortex 8:553-561

Lumer ED, Friston KJ, Rees G (1998) Neural correlates of perceptual rivalry in the human brain. Science 280:1930-1934

Malonek D, Dirnagl U, Lindauer U, Yamada K, Kanno I, Grinvald A (1997) Vascular imprints of neuronal activity: relationships between the dynamics of cortical blood flow, oxygenation, and volume changes following sensory stimulation. Proc Natl Acad Sci U S A 94:14826-14831

Menon RS, Goodyear BG (1999) Submillimeter functional localization in human striate cortex using BOLD contrast at 4 Tesla: implications for the vascular point spread function. Magn Res Med 41:230-235

Menon RS, Ogawa S, Strupp JP, Urgubil K (1997) Ocular dominance in human V1 demonstrated by functional magnetic resonance imaging. J Neurophysiol 77:2780-2787

Ogawa S, Lee TM, Nayak AS, Glynn P (1990) Oxygenationsensitive contrast in magnetic resonance image of rodent brain at high magnetic fields. Magn Reson Med 14:68-78
Ogawa S, Menon R, Tank DW, Kim SG, Merkle H, Ellermann JM, Ugurbil K (1993) Functional brain mapping by blood oxygenation dependent contrast magnetic resonance imaging. Biophysics J 64:803-812

Ohzawa I, DeAngelis GC, Freeman RD (1997) Encoding of binocular disparity by complex cells in the cat's visual cortex. J Neurophysiol 77:2879-2909

Poggio GF, Fischer B (1977) Binocular interaction and depth sensitivity in striate and prestriate cortex of behaving rhesus monkey. J Neurophys 40:1392-1405

Rutschmann RM, Greenlee MW (2002) Human cortical areas responding to binocular disparity: an fMRI study. (submitted for publication)

Smith AT, Greenlee MW, Singh KD, Kraemer FM, Hennig J (1998) The processing of first- and second-order motion in human visual cortex assessed by functional magnetic resonance imaging (fMRI). J Neurosci 18:3816-3830

Talairach J, Tournoux P (1988) Co-planar stereotaxic atlas of the human brain. Thieme, Stuttgart

Tootell RB, Reppas JB, Kwong KK, Malach R, Born RT, Brady TJ, Rosen BR, Belliveau JW (1995) Functional analysis of human MT and related visual cortical areas using magnetic resonance imaging. J Neurosci 15:3215-3230

Tootell RBH, Mendola JD, Hadjikhani NK, Ledden PJ, Liu AK, Reppas JB, Sereno MI, Dale AM (1997) Functional analysis of V3A and related areas in human visual cortex. J Neurosci 17:7060-7078

Turner R, Jezzard P, Wen H, Kwong KK, Le Bihan D, Zeffiro T, Balaban RS (1993) Functional mapping of the human visual cortex at 4 and 1.5 tesla using deoxygenation contrast EPI. Magn Reson Med 29:277-279 